\title{
Based on the Perspective of College Education, this Analysis of Student Work Management and Service
}

\author{
Jian Xu
}

Jiangxi Vocational Techlege Of Industry \& Trade, Jiangxi,Nanchang,330038

739960103@qq.com

\begin{abstract}
The work of college students is an important part of college education, with the popularization of higher education, the educational environment and educational objectives have also changed, colleges and universities should carry out reform according to the most current student work with the characteristics of the times, and deeply excavate the role that student work can bring. Traditional student work is usually dominated by explicit ideological and political education and rigid management, but the results obtained in this way are not high, and easy to cause students' rebellious psychology, so colleges and universities should actively seek innovative ways to achieve the goal of educating students through student work. Colleges and universities should do the "three full education" of full education, full education and all-round education, so that students can develop in an all-round way and cultivate high-quality talents who contribute to the country.
\end{abstract}

Keywords : College education, Student work management, Management and education, Service to educate people

\section{基于高校育人视角解析学生工作管理与服务}

徐健

\author{
江西工业贸易职业技术学院 江西 南昌 330038 \\ 739960103@qq.com
}

\section{摘要}

高校学生工作是高校育人的重要一部分, 随着高等教育的不断普及, 面临的教育环境与教育目标也发生了改变, 高校要根据时代特征最现今的学生工作进行改革, 要深入挖掘学生工作能够带来的育人作用。传统的学生工作 中通常以显性的思想政治教育和刚性的管理为主, 但这种方式获得的成效不高, 并且容易引起学生的反叛心理, 所以高校要积极寻求创新的方式, 以学生工作来实现育人目的。高校要做到全员育人、全程育人、全方位育人 的 “三全育人”，使得学生能够德智体美劳全面发展，培育出为国家做贡献的高素质人才。

关键词：高校育人；学生工作管理；管理育人；服务育人

\section{1. 新时代高校的学生工作}

习近平总书记在南昌大学视察时曾说: “希望当 代大学生珍惜韶华, 把学习成长同党和国家的事业紧 紧联系起来、同社会和人民的需要密切结合起来, 用 青春铺路, 让理想延伸。” 高校的学生工作要符合国 家与社会对人才的需要, 要树立学生正确的思想政治
观念。学生工作就是辅导员对学生做的种种工作, 其 中包含了对学生的日常管理、心理辅导、就业指导、 贫困生资助、住宿管理等等, 作为一名高校的辅导员, 其工作内容包含的范围广且多, 所以需要辅导员对学 生工作做好规划管理与服务。辅导员是大学生在学校 生活中接触最多的教师, 辅导员在构建大学生价值观、 人生观、世界观中占据了重要的地位, 辅导员要清楚 
的认识到自己的工作职责, 不仅仅要将学生事务处理 好, 还要在学生工作中做好思想政治工作，引导学生 健康积极向上。辅导员所做的学生工作是学校活动、 学校纪律与学生之间的一座桥梁, 每当学校举办活动 时, 辅导员要准确将学校的要求, 每个学生负责的事 务规整布置。在大学时学生经常会因为远离父母的管 束而懒惰下来, 学生的按时上课, 学生宿舍内卫生的 保持, 学生的按时返校等等学校纪律都需要辅导员在 其中起到监督的作用。学生工作的顺利进行, 能够保 持学校内的教学环境, 保证学生们认真学习, 教师们 认真教学。辅导员在进行学生工作时一定要注意工作 的方法和规律, 并将其在学生工作中牢牢把握、坚定 执行, 帮助学生在这过程之中顺利成人、成才。

管理是学生工作中的基础, 做好学生工作管理才 能保障接下来的学生工作的顺利进行。有些学生在学 习与生活之中存在着一定的不良习惯, 自我管理的能 力不足, 这时候就需要学生工作发挥作用。在进行学 生工作管理时, 应该将有目的的引导作为管理的最好 结果。在大学阶段, 虽然大部分学生已经成年, 心理 也基本成熟，有了基础的判断是非的能力，但心中的 理想信念依旧不够坚定，在对未来的规划中依然以功 利心作为未来发展方向规划的准则, 所以辅导员要以 各项学校的规章制度来管理学生, 培养学生的自律观 念与自律能力, 尊重与引导学生。同时辅导员也要做 好学生工作的服务, 以服务学生的理念来做好学生工 作。学生工作中的服务性能够很好的将高等教育的大 众化、国际化与学生服务很好的融合在一起。许多大 学生在面对一个全新的陌生的环境, 远离家乡与父母, 心中会出现畏惧的心理, 辅导员在这时候就要做好服 务工作, 引导学生在高校之中放松心态。同时学生工 作中有贫困补助、帮助就业等等方面的工作，辅导员 在做这些工作时也要秉持着服务学生的理念, 将学生 放在平等的位置, 解决学生的问题。新时代的学生工 作必须要保证以学生为主体, 双方平等尊重, 辅导员 要及时改变工作理念与工作方式, 有效解决学生面临 的现实问题。新时代学生工作中要明确辅导员在其中 的定位, 辅导员作为学校思想政治教育中的重要一环, 作为学生在校生活中接触最多的教师, 要承担起培养 学生的责任, 要将自己当成是学生的人生导师, 要积 极引导学生健康成长, 投身于社会与国家的建设当中 去, 培育出优秀的社会主义接班人。

\section{2. 高校学生工作存在的问题}

\section{1. 对学生工作理念不明确}

传统的学生工作中辅导员仅仅将学生工作作为 行政工作, 而没有意识到辅导员这个职位的特殊性, 辅导员要在其中发挥好教育学生的作用。并且许多辅 导员对学生的日常生活与学习并不关心, 仅仅将有没 有出事作为学生工作做的好与不好的评判标准, 于是 学生在面对辅导员时总有一种割裂的感受, 在平常学 习生活中辅导员很少出现, 但在发生某一些事情, 比
如发生遇到诈骗、心理评估结果不好等等事情时, 辅 导员就会突然出现, 对学生嘘寒问暖, 这样的学生工 作并不能让学生感受到温暖, 只会让学生对学生工作 产生抗拒心理, 这也会对辅导员后续的学生工作产生 阻碍。这也能够从对高校学生的调查中看出, 辅导员 在进行学生工作时的重点并不是做思想政治工作, 这 影响到了学生对学校学生工作的满意度。并且大部分 辅导员在遇到问题时面对学生采取的办法比较强硬, 并没有对学生的违规行为做出柔性的劝导, 而是一味 的给学生灌输正确的行为方式, 这样的方法并不能真 正的起到教育的作用, 还会引发学生的叛逆心理。许 多学生工作中辅导员仅仅将问题管理作为工作的重 点, 并没有认识到学生工作是要鼓励学生成长与发展, 给学生营造学习的氛围。

\section{2. 没有将学生放在主体位置}

高校传统的学生工作忽视了学生在其中的重要 性, 往往是将学生放在了被动接受的位置。传统的学 生工作中, 往往是学校下达通知, 辅导员履行通知中 的职责, 将通知转达给学生, 要求学生做相应的工作, 而这样的方式是一种从上至下的方式, 将学生放在了 整个高校体系的最底层, 只是让学生被动的接受与服 从, 这样的学生工作是无效的。传统的学生工作中并 没有对学生有足够的平等尊重, 将学生工作者放在了 主导的位置, 这样的学生工作方式忽视了学生在学生 工作中的主体位置, 高校与辅导员应该要在学生工作 中随着学生的要求与实际情况做出改变, 而不是主观 的忽视学生的发展需求, 仅仅将高校发展的目标一味 的安在了学生的头上, 让学生工作呈现出单向且主体 缺失的状况。这种学生工作方式对于高校与辅导员的 工作来说是简单了, 可其效果也是约等于没有, 高校 与辅导员的态度在一定方面也会影响学生的态度, 以 这样的方式进行学生工作, 违背了教育发展规律与基 本要求, 其展现的效果并不如预期中的那么完美, 校 园内也没有展现出美好的学习氛围。

\section{3. 学生工作方式单一}

高校传统的学生工作中辅导员所要履行的职责 就是管理与教育学生, 而辅导员所采取的教育方式一 贯为刻板的灌输性教育, 只是照本宣科的对学生强调 平时的行为规范, 而辅导员进行管理的方式也只是规 范学生的行为, 控制学生不要上课迟到, 定时对学生 宿舍进行检查, 用这种简单的方式进行学生工作, 主 要的工作目标就是保证学生在校的几年稳定生活, 也 没有想要对学生进行深入的思想政治教育的想法。从 对学生的问卷调查中就可以看出, 对学生进行思政政 治教育的辅导员还是少数, 一般辅导员与学生的谈话 内容也大部分是为了完成学校布置的任务, 谈论学生 事务。近年来高校学生工作所涵盖的内容越来越广, 辅导员身上的职责也越来越重, 许多辅导员为了减轻 工作负担, 于是也没有对学生工作进行创新与改进。 


\section{4. 大学生心理健康问题}

高校传统的学生工作中对学生的心理健康并不 重视, 从表格中学生表示的与辅导员交流最多的方面 中也能够看出，心理疏导占的比例比较少，可近年来 高校中学生由于学业压力大、就业压力大、情感上受 到打击、心理疾病等原因导致的自杀与伤害他人的事 件越来越多, 这些事件都应该给高校敲响警钟, 高校 与辅导员现今应该提升学生工作中对学生心理评估 以及心理疏导的比例。现在的大学生普遍经历的事情 较少, 心理调节与控制的能力比较差, 并且网络上繁 杂的信息他们无法很好的辨别, 所以就很容易导致心 理问题的出现。而现在许多高校内没有设立心理咨询 部门或是缺少专业的心理咨询人员, 于是无法很好的 解决学生的心理问题, 并且许多高校领导没有相关的 隐私概念, 心理咨询人员专业素养不够、学术背景层 次不齐, 高校学生进行心理咨询时透露的相关隐私内 容应该是需要保密的, 但许多高校心理咨询人员没有 职业道德, 随意将相关信息透露给高校领导、辅导员 或是学生, 这些事件的频发也使得学生对高校心理咨 询存在一定的恐惧心理。这些问题都是高校与辅导员 急需解决的重要问题。

表 1：对某高校学生进行的问卷调查结果

\begin{tabular}{|c|c|}
\hline \multicolumn{2}{|c|}{ 对所在高校学生工作的整体评价 } \\
\hline 非常满意 & $18 \%$ \\
\hline 满意 & $38 \%$ \\
\hline 不确定 & $25 \%$ \\
\hline 不满意 & $14 \%$ \\
\hline 很不满意 & $5 \%$ \\
\hline \multicolumn{2}{|c|}{ 与辅导员交流最多的方面 } \\
\hline 日常操行, 学生事务 & $63.3 \%$ \\
\hline 学业与职业规划 & $20 \%$ \\
\hline 谈心谈话, 答疑解惑, 心理疏导 & $17.7 \%$ \\
\hline 思想政治方面 & $14.3 \%$ \\
\hline 与辅导员关系不错, 经常闲聊 & $12.6 \%$ \\
\hline \multicolumn{2}{|c|}{ 学生认为对自己帮助与启发较多的人 } \\
\hline 任课老师 & $38.3 \%$ \\
\hline 辅导员 & $34.6 \%$ \\
\hline 父母 & $30.3 \%$ \\
\hline 系院书记 & $12.4 \%$ \\
\hline 其他人员 & 6. $4 \%$ \\
\hline
\end{tabular}

\section{3. 以高校学生工作管理与服务培育学生}

\section{1. 更新学生工作管理理念}

辅导员作为高校思想政治教育与学生管理中的 落实者与组织者, 需要承担好相应的责任, 树立正确 的职业观, 要在做好本职工作的同时做好学生工作的 管理与服务, 并且要在学生工作过程中实现管理育人 与服务育人。辅导员要确立好学生工作的目标, 要以 培育新时代优秀社会主义建设者作为工作的目标, 积 极提高自己的组织能力与协调沟通能力。学生工作中 要学会观察, 积极发展学生管理中出现的问题并及时 的进行改正, 要在学生工作中找到规律, 提升学生工 作管理的能力。在学生工作之中一定会有帮助辅导员 的学生, 辅导员在选择班长、学习委员、团委等等职 位之前, 要深入了解班级学生的实际能力, 要懂得知 人善任。辅导员在进行学生工作时要按照学生的个性 来对工作的实践过程进行调整, 要在学生工作中做到 个性化与针对性, 针对不同性格的学生辅导员要有不 同的沟通方式作出相应的引导, 这样进行的引导教育 可以促进学生与辅导员之间的交流, 还可以提升双方 的沟通效率, 让学生对辅导员产生信任感。同时辅导 员要在学生工作时注重学生工作管理的机制, 充分利 用激励机制和约束机制, 最大限度的调动学生学习、 参与活动的积极性。辅导员要创新学生工作, 促进学 生管理体系现代化。同时学生工作还要保持简单高效, 现在高校内时常会由于事务要学生们上交自己的材 料, 比如身份证号、手机号、父母姓名等等, 在这种 时候, 辅导员就不要一遍又一遍的反复要求学生提交 资料, 这样做的效率低, 浪费辅导员与学生的时间, 辅导员应该在做这种学生工作时以之前收集的为基 础, 提高学生工作的效率。

\section{2. 明确职责分工}

学生工作中虽然辅导员的作用占据主导地位, 但 高校中学生工作职能部门还是要明确自己在学生工 作中的位置与分工, 保持整体学生工作从理论到实践, 从教育部发布的通知到对学生的具体要求, 这其中的 程序要井然有序、有条不紊, 才能提高学生工作的效 率。学生工作部门要目标明确、操作性强、可持续发 展, 提高高校育人效率。还要整合各部门的资源, 明 确学生工作的目标, 使资源的利用更加有针对性与目 的性, 同时工作方向的确定还可以督促各部门积极高 效准确的完成工作任务, 激发工作的动力, 实现高校 育人目标。让高校中的各个部门充分运作, 还能够减 轻辅导员的工作负担, 让辅导员有更多的时间进行学 生管理与服务工作, 加强学生的心理健康辅导。

\section{3. 加强心理健康指导服务}

学生的心理健康是其人格品质与未来发展方向 的决定性因素。现在高校学生心理存在问题的比重较 高, 高校要直面这个重要的问题, 并积极建设心理健 
康指导服务。高校之内要建立专业的心理咨询室, 聘 请专业的心理咨询师能够随时在学生产生抑郁等不 好情绪时对学生进行心理干预, 并且高校与教师要积 极推广校园内的心理咨询室, 让学生知道其联系方式, 能够促使学生在遇到困难时及时询问专业人士。高校 还要注重学生隐私的保护, 确定心理咨询师的专业度, 同时不能对学生的相关隐私进行了解或干预, 增强学 生对心理咨询室的安全感, 以免学生对心理咨询室产 生猜疑之心。同时高校要开设心理健康课程, 在课程 之上引导学生心态积极向上, 普及心理健康知识, 展 开心理普查, 在一定程度上了解学生的心理状况, 并 且让学生有一定的心理健康知识, 能够对自己的心理 状况进行简单的评估。在心理健康课程之上, 还要教 会学生提高心理承受能力与控制情绪等等自我心理 调节能力。高校还要在学生工作之中添加学生心理问 题预警、危机干预机制, 要对学生心理健康问题早发 现、早干预, 防止学生做出极端举动, 发生极端事件。 辅导员也要在其中发挥作用, 与学生平等相处, 以朋 友的身份经常与学生聊天, 在聊天之中要了解到学生 近期的生活状况与心理状况, 在谈话之中安慰学生, 引导学生积极思考问题, 始终要为学生着想, 缓解学 生的心理压力。高校始终要牢记学生工作中的服务意 识, 要将学生放在学生工作的第一位, 以学生的需求 为工作的准则, 特别是学生心理健康方面更是需要高 校尤其注意把握好对学生进行心理干预与不侵犯学 生隐私空间的度, 不要让任何一方失衡。

\section{4. 完善就业创业指导服务}

对于学生来说, 就业创业问题是他们在大学期间 面临的主要问题, 也是许多学生心理压力的来源, 作 为培养社会与国家需要的人才的高等院校, 学生毕业 后的工作去向是检验高校教育成果的重要指标, 高校 应该始终将就业创业指导服务放在重要位置。高校要 积极开展就业创业教育, 根据国家教育部的要求开设 就业创业指导课程, 在课程之上要了解要学生所理想 的就业创业方向, 并积极向学生提供可行的办法, 鼓 励学生追求理想, 帮助学生实现理想。就业创业教育 之中, 还要激发学生的爱国热情, 鼓励学生就业创业 时选择为社会、为国家做贡献的岗位, 端正学生们的 就业观念, 现在许多学生都是抱着功利心进行学习的, 要转变学生的这种功利的就业观。并且高校要积极开 展招聘会活动, 不仅仅是要在学生毕业时开展, 也可 以在暑假前开展此类活动, 鼓励学生积极参加社会实 践, 提前感受职场氛围。高校还可以邀请优秀毕业生、 企业家来到校园内开展就业创业相关的讲座, 以成功 的经验来鼓励学生, 降低学生对就业创业的压力, 给 学生提供现实可行的方法。辅导员也要做好就业创业 指导服务, 充分了解学生在毕业后想要的工作方向, 积极利用自己的资源给学生介绍相关的实习工作, 给 学生提供相关的岗位信息, 最大程度的帮助学生就业 创业。

\section{5. 强化贫困生资助工作}

高校贫困生资助工作是学生工作中的重要一环, 这能够促进国家教育公平, 确保家庭经济困难学生顺 利完成学业。现在国家相关的政策已经十分完善, 国 家助学金、助学贷款、奖学金等等都能够确保一位贫 困生安心的在高校接受教育。高校的学生工作中为了 强化贫困生资助工作, 要加强其资助程序的监管力度, 确保助学金能够真正帮助到贫困的学生。高校还要健 全勤工助学的制度, 对于学生来说, 校外的兼职麻烦 且不够安全, 在校园内进行勤工助学是最好的办法, 在校园内有不少岗位可以提供给贫困的学生, 高校要 在官网或其他官方信息渠道发布相关的内容, 公开透 明的招聘勤工助学的学生, 让学生能够通过自己的能 力实现其价值, 自食其力。辅导员要基本了解学生的 经济状况, 对于家庭经济状况不好的学生要将其放在 助学金的名单之上, 鼓励学生参加有奖学金的比赛, 在一定程度上给学生提供帮助, 帮助贫困学生全面发 展, 不要让一些学生由于经济的困难而产生自卑心理 或是放弃学业。

\section{6. 加强党建建设}

想要在学生工作中充分发挥高校的育人功能, 就 必须要加强党建建设。学校要注重对团员干部或党员 干部的选拔与任用, 着重培养优秀的学生典型, 让学 生之间形成适当的竞争模式, 提高高校共青团、党支 部的综合素质。同时高校还要鼓励学生加入共青团、 加入预备党员之中, 让高校学生中形成对党的历史、 国家的历史学习的热潮, 形成学校优秀的学风与校风, 在高校校园内使学生与教师群体充分践行社会主义 核心价值观，培育出优秀的高素质人才。

\section{4. 结论:}

学生工作是连接学校与学生的重要环节, 高校应 该注重学生工作的管理与服务, 对学生工作进行深入 改革与创新, 坚决履行党在高校中的任务部署, 培养 出知行合一、有理想、有担当、有品质、有作为、有 修养的全方位发展的学生, 要让学生们成为实现中华 民族伟大复兴的主力军。高校要关注好学生工作中的 心理健康问题、学生工作管理问题、学生工作部署问 题与党建建设问题, 为学生提供好就业创业指导服务 与贫困生资助服务, 做到管理育人与服务育人的有机 统一，为社会主义发展而服务。

\section{REFERENCES}

[1] Wang Hui. Research on people-oriented value demands of college student work in the new era $[\mathrm{J}]$. Jiangsu higher education, 2019 (03): 100-103

[2] Liu zhikan. Basic dimensions and practical dimensions of college student work under the new 
normal of Higher Education [J]. Higher agricultural education, 2015 (04): 84-88

[3] Zhong Binglin. Study new problems and meet new challenges in college student affairs management [J]. China higher education, 2013 (23): 17-19

[4] Zhu Hong, Li Xuening. The relationship between college student work and student development in China -- what has been found in empirical research [J]. Higher education research, 2011,32 (08): 79-85

[5] Lang Wenxiang, Li Jiqing. Strengthening the construction of College Students' archives and helping college students' Entrepreneurship and employment $[\mathrm{J}]$. Journal of Anyang Institute of technology, 2021,20 (05): 43-45 